\title{
Evaluation and Clinical Significance of Jagged-1-activated Notch Signaling by APEX1 in Colorectal Cancer
}

\author{
HONG-BEUM KIM ${ }^{1 *}$, HYUN-JONG LIM ${ }^{2 *}$, HEE-JEONG LEE ${ }^{3}$, JUN HEE PARK $^{4}$ and SANG-GON PARK ${ }^{3}$ \\ ${ }^{I}$ Department of Premedical Course, Chosun University School of Medicine, Gwangju, Republic of Korea; \\ ${ }^{2}$ Department of Medicine, Gradulat School of Chosun University, Gwangju, Republic of Korea; \\ ${ }^{3}$ Department of Internal Medicine, Hemato-oncology, Chosun University Hospital, Gwangju, Republic of Korea; \\ ${ }^{4}$ Department of Otolaryngology Head and Neck Surgery, Chosun University Hospital, Gwangju, Republic of Korea
}

\begin{abstract}
Background/Aim: Colorectal cancer (CRC) is one of the most common in the world and its prevalence is rapidly increasing. Jagged-1-activated Notch signaling by apurinic/apyrimidinic endodeoxyribonuclease 1 (APEX1) promotes CRC, and high expression of Jagged-1 is associated with poor prognosis. However, its clinical implication is unknown. The aim of this study was to investigate the clinical role of Jagged-1-activated Notch signaling by APEXI. Materials and Methods: The 5-dimethylthiazol-2-yl) 2, 5-diphenyltetrazolium bromide (MTT) assay was used to evaluate the anti-cancer efficacy of 5-fluorouracil (5-FU), oxaliplatin, and irinotecan. Tissue from CRC patients was analyzed to assess the clinical specificity of Jagged-1 activated by APEX1. Results: The half-maximal inhibitory concentration $\left(I C_{50}\right)$ in cells co-expressing APEXI and Jagged-1 cells was higher than that in cells expressing only APEXI. These results indicated that the simultaneous expression of APEXI and Jagged-1 might be associated with chemoresistance toward 5$F U$, oxaliplatin, and irinotecan. Analysis of tissue from CRC patients revealed that high expression of Jagged-1 was associated with a statistically significantly low response to chemotherapy. Conclusion: Overexpression of Jagged-1 by APEXI might serve as a predictor of response to chemotherapy and of poor prognosis, and moreover may be a therapeutic target for chemotherapy of advanced CRC.
\end{abstract}

\footnotetext{
*Hong-Beum Kim and Hyun-Jong Lim contributed equally to this study as co-first authors.

Correspondence to: Sang-Gon Park MD, Ph.D., Department of Internal Medicine, Hemato-oncology, Chosun University Hospital, 365 Pilmun-daero, Dong-gu, Gwangju 61453, Republic of Korea. Tel: +82 622203984, Fax: +82 622349653, e-mail: sgpark@chosun.ac.kr

Key Words: Apurinic/apyrimidinic endodeoxyribonuclease 1 (APEX1), chemotherapy, chemoresistance.
}

Colorectal cancer (CRC) is the third most prominent cancer globally. The prevalence of CRC is rapidly increasing. Surgical resection is the only method of cure. In the case of advanced, metastatic, or recurrent cancers that are not operable, palliative chemotherapy in combination with targeted therapy is the standard treatment option. Approximately $80 \%$ of CRCs are localized in the bowel wall and/or its regional lymph nodes. In the remaining $20 \%$ of patients who are diagnosed with de novo unresectable metastatic $\mathrm{CRC}$ and in patients with stage II/III CRC (approximately 40\% of all CRC patients), recurrence occurs despite curative surgery. Unresectable and metastatic CRC is incurable and requires palliative systemic chemotherapy $(1,2)$.

Apurinic-apyrimidinic endonuclease 1 (APEX1) is one of the proteins that is essential for base excision repair. APEX1 overexpression is correlated with cancer progression in various human solid malignancies (3-6). Furthermore, APEX1 reportedly contributes to CRC progression through the upstream activation of the Jagged-1/Notch signaling pathway (7) and high expression of jagged-1 is associated with poor prognosis after curative surgery for CRC (8). Moreover, a study reported that Jagged-1 activated by APEX1 acts as an anti-cancer drug resistance factor in advanced biliary cancer (9). Jagged-1 is a Notch receptor ligand that enhances Notch signaling. The activation of Notch signaling plays an important role in the development and progression of various malignant tumors (10-13).

In this study, we investigated the clinical significance of Jagged-1-activated Notch signaling by APEX1 in CRC.

\section{Materials and Methods}

Cell culture. Human CRC cell lines (HCT-15, SW620, HCT-116, Caco-2, DLD-1, SW480, and LoVo) were cultured in RPMI1640 medium supplemented with $10 \%$ heat-inactivated fetal bovine serum (FBS, Lonza, Alpharetta, GA, USA), 100 units/ml penicillin, and $100 \mu \mathrm{g} / \mathrm{ml}$ streptomycin (Invitrogen, Carlsbad, CA, USA). Caco-2 human CRC cells were grown in MEM with 20\% FBS. All the cell 
lines were acquired from the American Type Culture Collection (ATCC, Manassas, VA, USA) and maintained in a humidified incubator with an atmosphere of $5 \% \mathrm{CO}_{2}$ at $37^{\circ} \mathrm{C}$.

Preparation of drug solutions to perform in vitro assays. Aqueous solutions of all the drugs were prepared in distilled water and stored in a deep freezer. 5-fluorouracil (5-FU), oxaliplatin, and irinotecan (Sigma, St Louis, MO, USA) were prepared as aqueous solutions of $10 \mathrm{mg}$ in $20 \mathrm{ml}, 250 \mathrm{mg}$ in $5 \mathrm{ml}$, and $40 \mathrm{mg}$ in $2 \mathrm{ml}$, respectively.

3-(4, 5-Dimethylthiazol-2-yl)-2, 5-diphenyltetrazolium bromide (MTT) assay. Cell viability was determined by using an MTT assay according to the standard protocol. Cells were seeded in wells of a 96-well plate and incubated for $24 \mathrm{~h}$. These cells were treated with 5-FU, oxaliplatin, or irinotecan for $24 \mathrm{~h}$. After treatment, $10 \mu \mathrm{l} \mathrm{MTT}$ $(1 \mathrm{mg} / \mathrm{ml})$ in phosphate buffered saline (PBS) was added on the cells and incubation was continued for $4 \mathrm{~h}$ at $37^{\circ} \mathrm{C}$. Subsequently, the medium containing MTT was removed, $100 \mu$ dimethyl sulfoxide (DMSO) was added, and the cells were incubated for another $20 \mathrm{~min}$ at $37^{\circ} \mathrm{C}$ with gentle shaking. The absorbance was read using an ELISA plate reader (Tecan, Trading AG, Switzerland) with a 570-nm filter. Cell viability was calculated based on the relative color intensity of treated and untreated samples.

Small interfering RNA (siRNA)-mediated APEX1 knockdown. To knockdown APEX1 expression, the cells were transiently transfected with specific siRNA using Lipofectamine RNAiMAX (Invitrogen) according to the manufacturer's instructions. The sequence used to target APEX1 was 5'-AAGTCTGGTACGA CTGGAGTA-3', while that for the negative control siRNA (Bioneer, Daejeon, Korea) was 5-'CCUACGCCACCAAUU UCGUdTdT-3'. The cells were transfected with either pSilencer2.1U6-neo control shRNA or pSilencer2.1-U6-neo APEX1 shRNA using Lipofectamine 2000 (Invitrogen, Carlsbad, CA, USA) and cultured in a selection medium containing $500 \mu \mathrm{g} / \mathrm{ml}$ neomycin for 2 to 3 weeks.

Immunoblotting. Cells were washed with $1 \times$ PBS and lysed in lysis buffer (20 mM HEPES (pH 7.4), 2 mM EGTA, 50 mM glycerol phosphate, $1 \%$ Triton X-100, 10\% glycerol, $1 \mathrm{mM}$ dithiothreitol, 1 $\mathrm{mM}$ phenylmethyl sulfonyl fluoride, $10 \mu \mathrm{g} / \mathrm{ml}$ leupeptin, $10 \mu \mathrm{g} / \mathrm{ml}$ aprotinin, $1 \mathrm{mM} \mathrm{Na} \mathrm{VO}_{4}$, and $5 \mathrm{mM} \mathrm{NaF}$ ). The protein concentration was determined using a dye-binding microassay (BioRad, Hercules, CA, USA). Equal amounts of cellular or tissue proteins were resolved by $8-12 \%$ sodium dodecyl sulfatepolyacrylamide gel electrophoresis (SDS-PAGE) followed by the electrophoretic transfer of protein bands onto a polyvinylidene difluoride membrane (PALL Life Sciences, NY, USA). The membranes were blocked for $1 \mathrm{~h}$ with Tris-buffered saline-Tween [TBS-T; $10 \mathrm{mM}$ Tris- $\mathrm{HCl}(\mathrm{pH} \mathrm{7.4)}$ and $150 \mathrm{mM} \mathrm{NaCl}$, and $0.1 \%$ Tween-20] containing 5\% non-fat milk and incubated with specific primary antibodies overnight at $4^{\circ} \mathrm{C}$. The blots were washed four times for 15 min per wash with TBS-T and incubated for $1 \mathrm{~h}$ with corresponding peroxidase-conjugated secondary antibodies (1:4000 dilution; Jackson Immuno Research Inc, West Grove, PA, USA). The blots were washed four times with TBS-T and developed using an enhanced chemiluminescence (ECL) detection system (iNtRON Biotechnology, Gyeonggi, Korea). The antibodies used, mouse antiAPEX1 (sc-17774) and mouse anti-Jagged-1 (sc-390177), were purchased from Santa Cruz Biotechnology (Dallas, TX, USA).

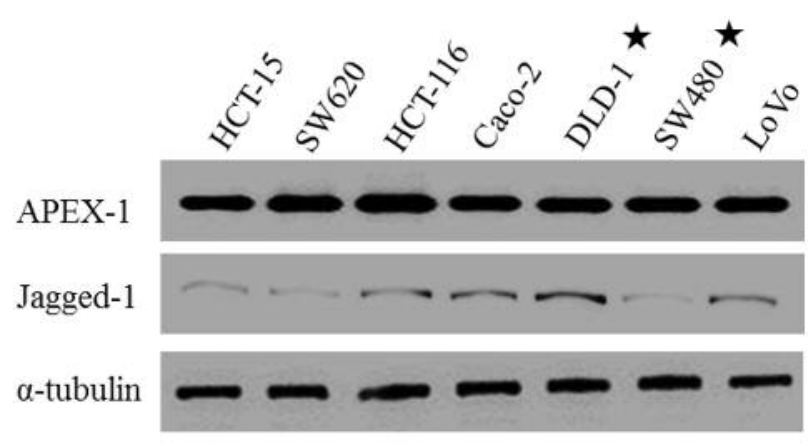

Figure 1. Western blotting revealed high APEX1 expression in all the colorectal cancer (CRC) cell lines. HCT-116, Caco-2, DLD-1, and LoVo cells expressed also high levels of Jagged-1. The star symbols indicate the cell lines selected for further experiments; DLD-1 cells exhibited strong expression of both the proteins, and SW480 cells exhibited strong expression of APEX1 but not Jagged-1.

Analysis of CRC tissue. The clinical specificity of Jagged-1 activated by APEX1 was analyzed in vivo in tissues acquired from CRC patients. The protocol was approved by Chosun University Hospital Ethics Committee. Patients with metastatic or recurrent CRC were enrolled through retrospective chart review. Of these patients, subjects who had received appropriate first-line chemotherapy and had been evaluated concerning their response, were available for follow-up, and had good performance status (Eastern Cooperative Oncology Group 0-1), and normal liver, kidney, and bone marrow function, were selected. CRC tissue samples were paraffin embedded and sectioned. Immunohistochemical staining and clinical examination were performed.

Immunohistochemistry. The aforementioned CRC tissue samples were obtained from the Chosun University Department of Pathology Tissue Bank. Tissue sections were stained with mouse anti-APEX1 (sc-17774; 1:500; Santa Cruz Biotechnology) or mouse anti-Jagged 1 (sc-390177; 1:300; Santa Cruz Biotechnology) antibodies. For immunohistochemistry, a biotinylated goat anti-mouse antibody (Vector Laboratories, Burlingame, CA, USA) followed by horseradish peroxidase-conjugated streptavidin (Vector Laboratories) was used. After immuno-labeling, specimens were briefly counterstained with hematoxylin. Immunolabeled images were captured using a model C-4040Z digital camera (Olympus Corp, Lake Success, NY, USA) and model BX-50 microscope (Olympus Corp, Lake Success, NY, USA). Protein expression was scored in the nucleus for APEX1 and in the plasma membrane and cytoplasm for Jagged-1. APEX1 and Jagged-1 immunoreactivities were determined by scoring for staining intensity $(0$, none; 1 , weak; 2 ; moderate; 3 , strong) and percent of positive cells $(0,<5 \% ; 1,6 \%$ $25 \% ; 2,26 \%-50 \% ; 3,50 \%-75 \% ; 4,>76 \%$ ), and the product of both scores being the final value.

Statistical analysis. Data in all the experiments are presented as the mean \pm standard deviation. Statistical comparisons were performed using two-tailed paired Student's $t$-test. A $p$-value $<0.01$ indicated a statistically significant difference. Kaplan-Meier analyses was used and the log-rank Mantel-Cox test was employed to determine any 

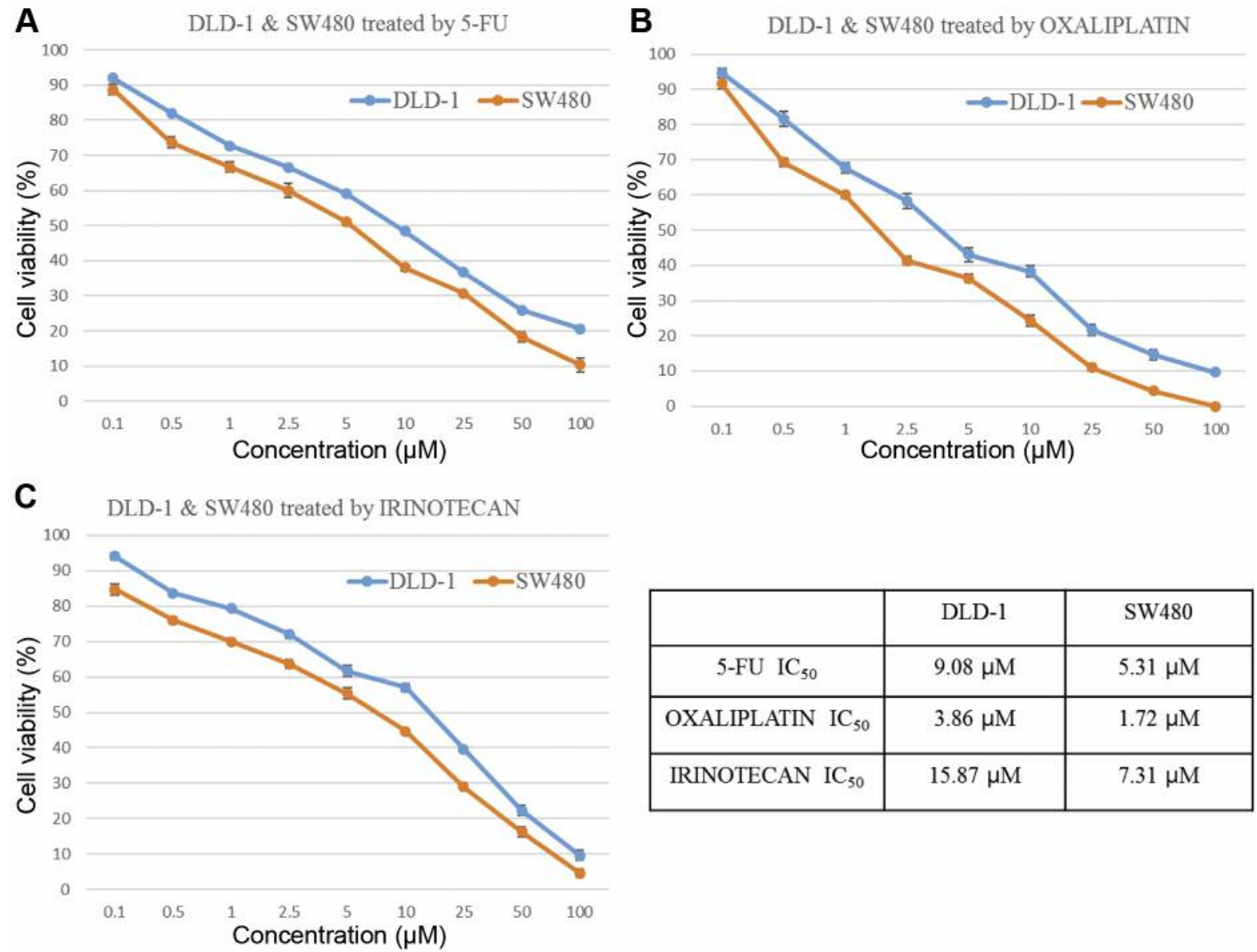

\begin{tabular}{|c|c|c|}
\hline & DLD-1 & SW480 \\
\hline 5-FU IC 50 & $9.08 \mu \mathrm{M}$ & $5.31 \mu \mathrm{M}$ \\
\hline OXALIPLATIN IC $_{50}$ & $3.86 \mu \mathrm{M}$ & $1.72 \mu \mathrm{M}$ \\
\hline IRINOTECAN IC $_{50}$ & $15.87 \mu \mathrm{M}$ & $7.31 \mu \mathrm{M}$ \\
\hline
\end{tabular}

Figure 2. MTT assay to assess the efficiency of 5-FU (A), oxaliplatin (B), and irinotecan $(C)$ in colorectal cancer $(C R C)$ cells. As shown in the table, the IC50 values were 1.7-fold (5-FU), 2.2-fold (oxaliplatin, and 2.2-fold (irinotecan) higher in DLD-1 cells than in SW480 cells.

statistical difference between the survival curves of the cohorts. The analysis was performed using GraphPad Prism (GraphPad) and Excel (Microsoft) software. Statistical analysis of clinical data was performed using SPSS version 21.0 software.

\section{Results}

Estimation of APEX1 expression in CRC cell lines. Constituent expression of APEX1 and Jagged-1 was examined in HCT-15, SW620, HCT-116, Caco-2, DLD-1, SW480, and LoVo CRC cell lines. APEX1 and Jagged-1 expression was detected by western blotting using $\alpha$-tubulin as a loading control. This analysis revealed that APEX1 was highly expressed in all the $\mathrm{CC}$ cell lines, with the additional high expression of Jagged-1 in HCT-116, Caco-2, DLD-1, and LoVo cells (Figure 1). In particular, DLD-1 cells coexpressed high levels of APEX1 and Jagged-1, while SW480 cells expressed only APEX1 (Figure 1). DLD-1 and SW480 cell lines were selected for subsequent experiments.
Efficiency of chemotherapeutic drugs. The MTT assay was performed to assess the sensitivity of DLD-1 and SW480 cells toward three established chemotherapeutic compounds 5-FU, oxaliplatin, and irinotecan (Figure 2). DLD-1 cells were more resistant to the three compounds compared to SW480 cells. Determination of the half-maximal inhibitory concentration (IC50) of each compound revealed higher values for 5-FU, oxaliplatin, and irinotecan in DLD-1 cells than in SW480 cells (1.7-fold, 2.2-fold, and 2.2-fold higher, respectively) (Table $\mathrm{I}$ ). These results showed that the simultaneous expression of APEX1 and Jagged-1 is associated with chemoresistance toward 5-FU, oxaliplatin, and irinotecan.

Jagged-1 expression after APEX1 knockdown. The variation in APEX1 and Jagged-1 expression levels in DLD-1 and SW480 cell lines after APEX1 knockdown was determined. To knockdown APEX1, either APEX1 or control siRNA was 
Table I. MTT assay to assess the efficiency of chemotherapeutic drugs in two colorectal cancer (CRC) cell lines.

\begin{tabular}{lcc}
\hline & DLD-1 & SW480 \\
\hline 5-FU $\left(\mathrm{IC}_{50}\right) \mu \mathrm{g} / \mathrm{ml}$ & 8.87 & 5.24 \\
Oxaliplatin $\left(\mathrm{IC}_{50}\right) \mu \mathrm{g} / \mathrm{ml}$ & 3.64 & 1.83 \\
Irinotecan $\left(\mathrm{IC}_{50}\right) \mu \mathrm{g} / \mathrm{ml}$ & 14.26 & 7.04 \\
\hline & DLD-1/siAPEX1 & \multirow{2}{*}{ SW480/siAPEX1 } \\
\hline 5-FU $\left(\mathrm{IC}_{50}\right) \mu \mathrm{g} / \mathrm{ml}$ & 5.08 & 4.95 \\
Oxaliplatin $\left(\mathrm{IC}_{50}\right) \mu \mathrm{g} / \mathrm{ml}$ & 1.92 & 1.67 \\
Irinotecan $\left(\mathrm{IC}_{50}\right) \mu \mathrm{g} / \mathrm{ml}$ & 7.15 & 6.11 \\
\hline
\end{tabular}

transfected into DLD-1 and SW480 cells. Western blot analysis revealed that transfection with APEX1-siRNA resulted in an approximately $80 \%$ reduction in the levels of endogenous APEX1 in both DLD-1 and SW480 cells compared to the control siRNA transfected cells. In DLD-1 cells, Jagged-1 expression was clearly decreased after APEX1 knockdown (Figure 3), suggesting that Jagged-1 expression was induced by APEX1.

Efficiency of chemotherapeutic drugs after APEXI knockdown. The variation in drug sensitivity of DLD-1 and SW480 cells after APEX1 knockdown was assessed. After APEX1 knockdown, the chemoresistant DLD-1 cells were rendered sensitive to 5-FU, oxaliplatin, and irinotecan, with a remarkable decrease in $\mathrm{IC}_{50}$ values compared to cells that constituently expressed APEX1 (approximately 44\%, 50\%, and $44 \%$ decrease in $\mathrm{IC}_{50}$ for 5-FU, oxaliplatin, and irinotecan, respectively). However, the $\mathrm{IC}_{50}$ of the inherently chemosensitive SW480 cells was not decreased significantly after APEX1 knockdown compared to normal cells (approximately $5.5 \%, 8.7 \%$, and $13.2 \%$ reduction in $\mathrm{IC}_{50}$ for 5-FU, oxaliplatin, and irinotecan, respectively) (Figure 4, Table I). These results suggested that increased expression of Jagged-1 following APEX1 stimulation might be a major chemoresistance pathway compared to APEX1 expression alone in colon cancer.

Clinical evaluation. Thirty patients treated at Chosun University Hospital met the inclusion criteria. Immunohistochemical staining for APEX1 and Jagged-1 was performed on CRC tissues obtained from these patients. The protein expression scores were calculated and the final score determined as described in the Materials and Methods. Clinical information was analyzed by retrospective chart review. The response rate of each of the first-line chemotherapies was evaluated according to the RECIST criteria 1.1 version (Table II). Fourteen patients (36.8\%)

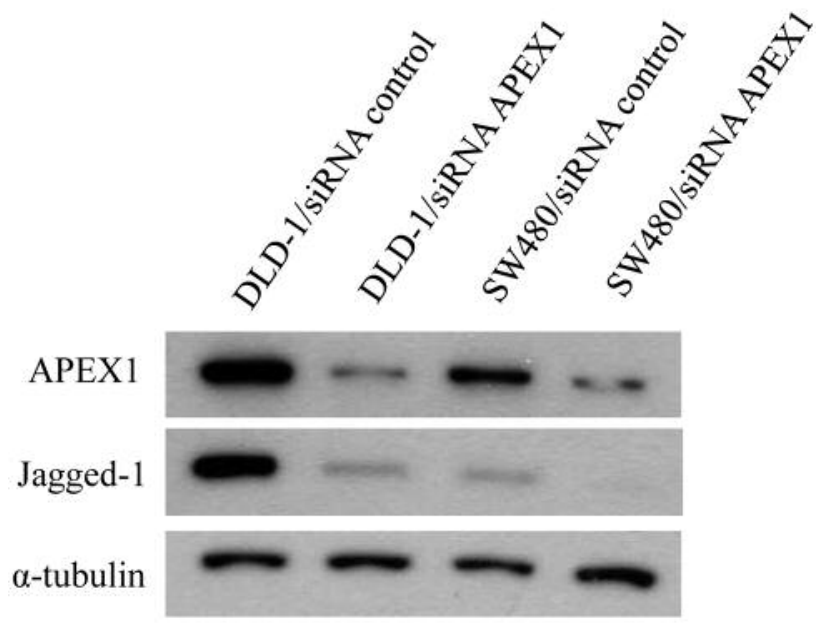

Figure 3. Western blotting of APEX1 and Jagged-1 expression in colorectal cancer (CRC) cell lines DLD-1 and SW480 after APEX1 knockdown. Jagged-1 expression in DLD-1 cells was prominently decreased after APEX1 knockdown.

displayed a complete or partial response, 12 (31.4\%) had stable disease, and 12 (31.6\%) displayed disease progression. These results were similar to those of conventional chemotherapy for CRC.

The mean protein expression score of APEX1 and Jagged1 was determined. The mean score of APEX1 in the responsive, stable, and progressive group was $2.57,3.5$, and 3.5, respectively. Cell viability, determined by the MTT assay revealed that there was no statistically significant association between the mean value of the APEX1 expression score and the anti-cancer response. The mean score of Jagged-1 expression in the responsive, stable, and progressive group was $1.71,3.5$, and 3.42 , respectively; the value of the responsive group was statistically significantly different from that of the non-responsive group (partial response and stable disease, $3.21 ; p=0.006)$. The mean value of the disease control group (partial response and stable disease, 2.30) was not statistically significant different from that of the progressive group.

Tissue staining was scored on the basis of cytoplasmic membrane and cytoplasm for Jagged 1 and nuclei for APEX1. Also, the sum of the weak point (score 1) and the presence of $5 \%$ positive cells within $5 \%$ (score 1 ) were determined as 2 , and was the reference point. Therefore, cases in which the total sum of the Jagged-1 score exceeded 2 points were classified as positive. The mean values of APEX1 and Jagged-1 according to the anti-cancer response were examined. This result also showed that a reference point of 2 had sufficient discrimination power, which was consistent with the results of a study on bile duct cancer (9). Presently, 

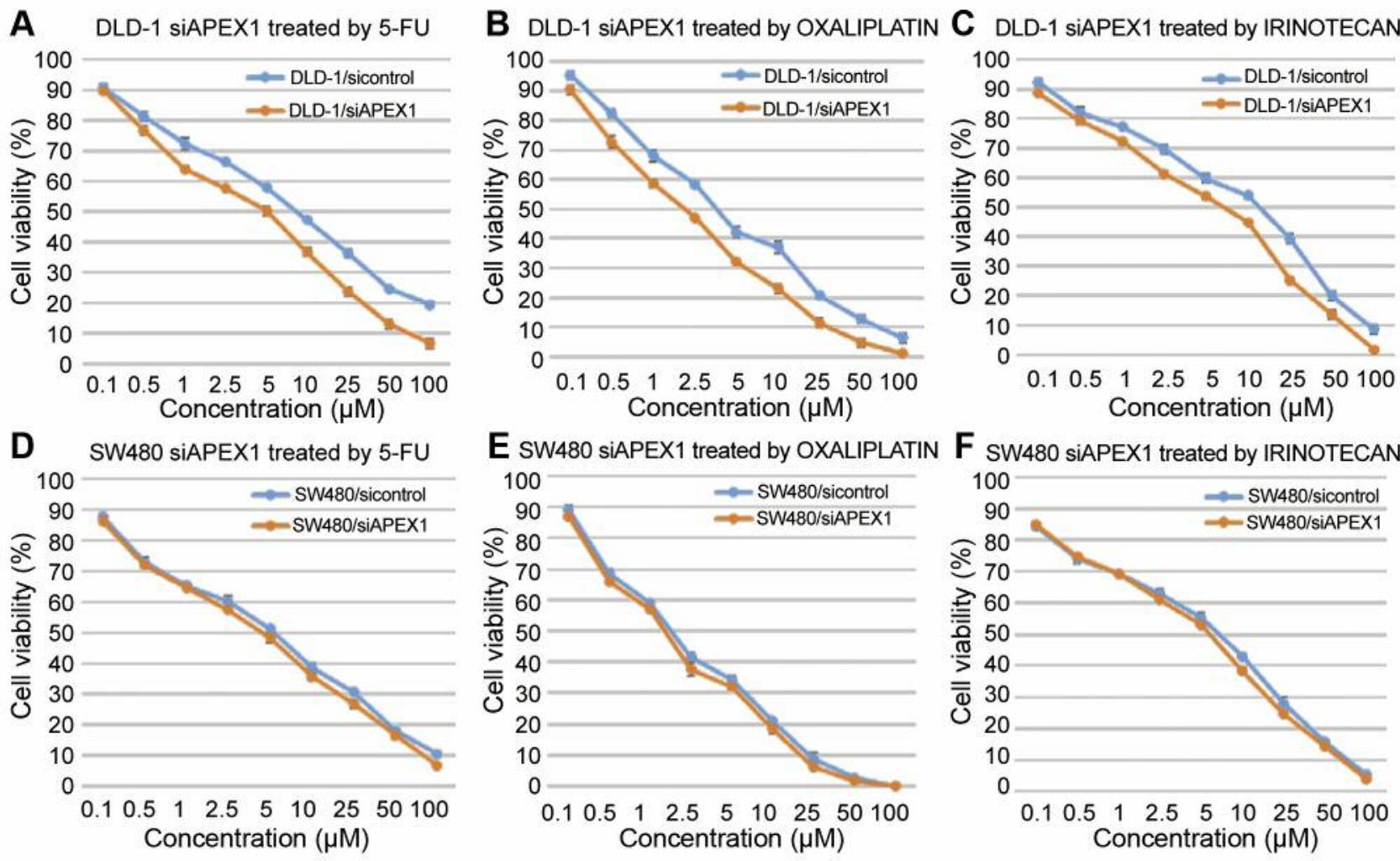

Figure 4. MTT assay to assess the efficiency of chemotherapeutic drugs in colorectal cancer (CRC) cells. Cells were seeded in wells of 96-well plates and treated with oxaliplatin or 5-FU. After APEX1 knockdown, the MTT assay performed using the chemosensitive DLD-1 cell line revealed a prominent decrease in the $I C_{50}$ values of chemotherapeutic agents (approximately 44\%, 50\%, 44\% for 5-FU (A), oxaliplatin (B), and irinotecan (C), respectively). The chemoresistant $S W 480$ cell line exhibited a minimal decrease in the $I C_{50}$ values of chemotherapeutic agents (approximately $3.4 \%, 6.7 \%$, and 13.2 for $5-F U(D)$, oxaliplatin $(E)$ and irinotecan $(F)$, respectively).

Table II. Immunohistochemistry scoring of metastatic or recurrent colorectal cancer patients according to the chemotherapy response (1st line chemotherapy best response: RECIST criteria version 1.1).

\begin{tabular}{lccc}
\hline & $\begin{array}{c}\text { Partial response } \\
(\mathrm{n}=14)\end{array}$ & $\begin{array}{c}\text { Stable disease } \\
(\mathrm{n}=12)\end{array}$ & $\begin{array}{c}\text { Progressive disease } \\
(\mathrm{n}=12)\end{array}$ \\
\hline Response & & & \\
$(p<0.05)$
\end{tabular}

Bold value represents significance.

of the 38 cases, 21 displayed a total Jagged-1 score $>2$ (positive) and 17 displayed a total score $<2$ (negative). There were no significant differences between the positive and negative groups concerning age, gender, location of the cancer, pathologic classification, and the type of chemotherapy. However, the response rate to chemotherapy in the positive group was statistically significantly less than that in the negative group (14.3\% vs. 64.7\%; $p=0.002)$ (Table III), suggesting that the expression of Jagged-1 was related to resistance to chemotherapy. The survival rate was 
Table III. Clinical and pathological characteristic of metastatic or recurrent colorectal cancer $(n=38)$.

\begin{tabular}{|c|c|c|c|}
\hline & $\begin{array}{l}\text { Jagged-1 positive } \\
(\text { score }>2) n=21\end{array}$ & $\begin{array}{l}\text { Jagged-1 negative } \\
(\text { score } \leq 2) \mathrm{n}=17\end{array}$ & $p$-Value \\
\hline Age, years (median) & 61 & 61.6 & 0.985 \\
\hline \multicolumn{4}{|l|}{ Gender } \\
\hline Male & $11(52.4 \%)$ & $10(58.8 \%)$ & \\
\hline Female & $10(47.6 \%)$ & $7(41.2 \%)$ & 0.752 \\
\hline \multicolumn{4}{|l|}{ Site } \\
\hline Ascending & $5(23.8 \%)$ & $2(11.8 \%)$ & \\
\hline Transverse & $2(9.5 \%)$ & $2(11.8 \%)$ & \\
\hline Descending, Sigmoid rectum & $8(38.1 \%)$ & $7(41.2 \%)$ & \\
\hline $6(28.6 \%)$ & $6(35.3 \%)$ & 0.815 & \\
\hline \multicolumn{4}{|l|}{ Histology } \\
\hline Clear differentiation & $1(4.8 \%)$ & 0 & \\
\hline Moderate differentiation & $16(76.2 \%)$ & $12(70.6 \%)$ & \\
\hline Poor differentiation & $2(9.5 \%)$ & $2(11.8 \%)$ & \\
\hline Mucinous carcinoma & $2(9.5 \%)$ & $3(17.6 \%)$ & 0.714 \\
\hline \multicolumn{4}{|l|}{ Chemotherapy response } \\
\hline Response rate & $3(14.3 \%)$ & $11(64.7 \%)$ & 0.002 \\
\hline Disease control rate & $11(52.4 \%)$ & $15(88.2 \%)$ & 0.034 \\
\hline \multicolumn{4}{|l|}{ 1st line chemo regimen } \\
\hline FOLFOX & $17(81 \%)$ & $13(76.5 \%)$ & \\
\hline FOLFIRI & $4(19 \%)$ & $4(23.5 \%)$ & 1 \\
\hline
\end{tabular}

Bold values represent significance.

not statistically significantly different between the negative group and the positive group ( $p=0.476$ ), although patients in the negative group displayed a tendency toward longer survival (28.4 months vs. 16.2 months) (Figure 5). However, this might be due to the low number of parameters evaluated.

The collective results suggested that the co-expression of APEX1 and Jagged-1 might be important in the anti-cancer drug resistance of CRC cells, with the main chemoresistance mechanism being APEX1-induced increased Jagged-1 activation . The findings from the clinical analysis confirmed the clinical implication of Jagged-1 activated Notch signaling by APEX 1 as a chemoresistance factor and an indicator of poor prognosis.

\section{Discussion}

The development of chemotherapy to treat CRC began with the identification of 5-FU in $1957(14,15)$. In the early 2000s, novel combinations of cytotoxic chemotherapeutic agents to treat CRC were established following the development of the novel drugs irinotecan (topoisomerase I inhibitor) and oxaliplatin (third-generation platinum agent) $(16,17)$. The development of combination chemotherapy and targeted therapy increased the response and survival rates in CRC patients. However, the associated cytotoxicity of these therapies was a problem. The individual administration of either of the representative cytotoxic combination therapies involving 5-FU,

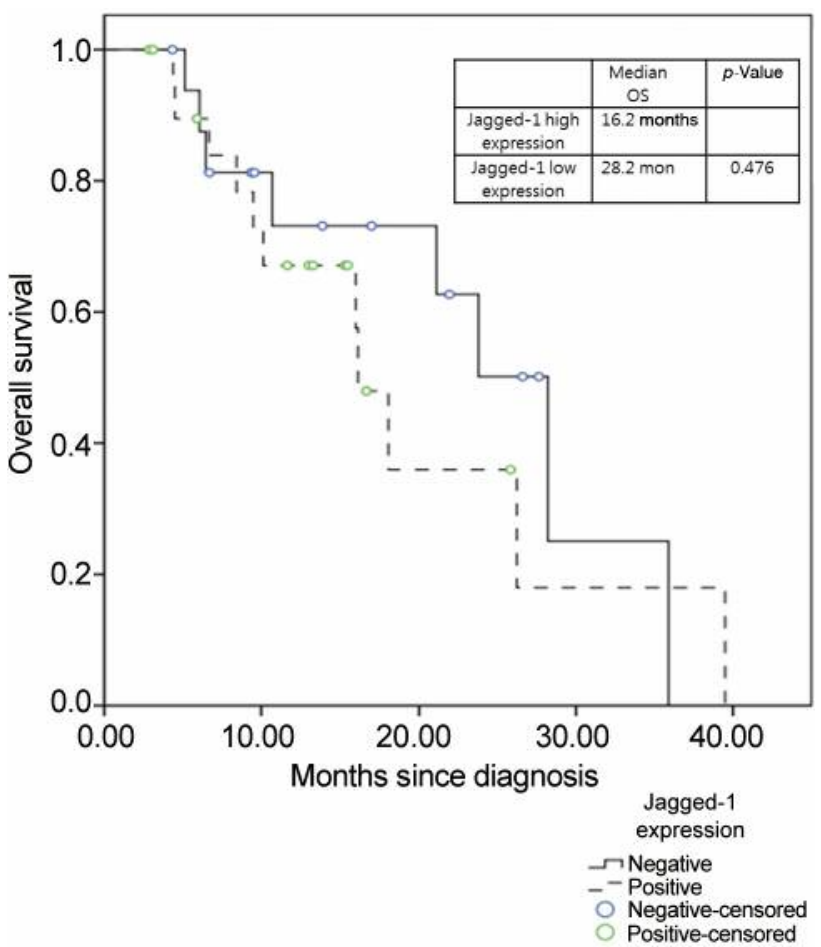

Figure 5. Overall survival (OS) rate analysis using a Kaplan-Meier curve. There was no difference in the survival time between the negative and positive groups (28.4 vs. 16.2 months; $p=0.476$ ). 
leucovorin, and oxaliplatin (FOLFOX) and 5-FU, leucovorin, and irinotecan revealed an overall survival rate $<2$ years owing to chemotherapy resistance in CRC patients (18-22).

The major challenge of cytotoxic chemotherapy is the development of resistance against chemotherapeutic agents. Chemoresistance has been studied for a long time and various theories have been proposed. However, as the chemoresistance mechanism involves complex processes, it cannot be understood through a single process $(23,24)$.

APEX1 is a multifunctional protein that is essential to perform base excision repair. The major function of APEX1 is to repair the single-strand DNA cleavage and apurinic/apyrimidinic sites. Abnormal APEX1 overexpression has been described in various solid tumors. Multiple studies have revealed the association of APEX1 with cancer progression and poor prognosis (3-6).

Notch signaling plays a major role in the determination of cell fate and maintenance of the progenitor cell population during embryonic development $(10,11)$. Activation of Notch signaling has emerged as an important aspect of research and recent reports have suggested that it plays an important role in the development and progression of numerous human malignant solid tumors $(12,13)$. Jagged-1 is one of the five Notch receptor ligands. Jagged-1 enhances Notch signaling and affects the growth of various cancers by regulating the survival rate of cancer stem cells. This improved survival of cancer stem cells might in turn improve the survival rate and reduce apoptosis of cancer cells, which could stimulate the proliferation and metastasis of cancer cells. Clinically, high Jagged-1 expression levels have been reported to be a poor prognostic factor in many cancers. Concerning the Notch signaling pathway, several cancers that feature Jagged-1 overexpression feature poor prognosis. However, the clinical role and importance of Notch signaling in colon cancer remain contentious; it is known that APEX1 activates Notch signaling via Jagged-1 and promotes CRC progression (25-28).

A report has revealed an association between the CRC progression and APEX1 mediated Jagged-1 upregulation. In this study, APEX1 stimulated tumorigenesis in noncancerous cells as well as CRC cell lines. It was demonstrated that APEX1 activates Notch signaling through Jagged-1 activation, and that this signal promoted the progression of CRC. Other reports have positively correlated APEX1 expression with the expression of Jagged-1 and cleaved Notch in human CRC tissue $(7,29,30)$.

Presently, the simultaneous expression of APEX1 and Jagged-1 was considered a major chemoresistance factor. APEX1-induced expression of Jagged-1 appears to be important in the chemoresistance to $5 \mathrm{FU}$, oxaliplatin, and irinotecan in CRC. Targeting the Notch signaling pathway to overcome drug resistance of cancer therapy has been explored and AEPX1-induced Jagged1 expression has been associated with chemoresistance in biliary cancer $(9,28)$.
However, the role of APEX1 or Notch signaling through the Jagged-1 activation in chemoresistance has not been previously investigated in CRC. The Notch pathway plays an important role in normal stem cells as well as cancer stem cells (31-33). Cancer stem cells are a specific and distinct cell subpopulation within a tumor. The cells have the abilities of self-renewal and differentiation to diverse cancer cell types. Cancer stem cells have increased invasive potential and resistance to several anti-cancer treatments, and may be responsible for patient relapse and metastasis. These cells have been identified in several tumor types, including CRC (34-36). Activation of CRC stem cells by AEPX1mediated Jagged1 expression has been hypothesized to be the most important cause of chemoresistance mechanism.

In conclusion, the collective data presented here reveal an association between the progression of CRC and APEX1mediated Jagged-1 upregulation. The simultaneous overexpression of APEX1 and Jagged-1 might be a major anticancer drug resistance factor in CRC patients. Concordant with the results of previous studies, we conclude the Notch signaling activation via APEX1-induced Jagged-1 activation is one of the major pathways of resistance to standard chemotherapy in CRC. The co-expression of APEX1 and Jagged-1 might be used as a potential biomarker to predict poor response to chemotherapy in CRC. The pathway that involves Notch signaling activation via APEX1-induced Jagged-1 activation might also be a major therapeutic target in cases of chemoresistant CRC. Further clinical studies will be needed to confirm this therapeutic strategy.

\section{Conflicts of Interest}

The Authors have no conflicts of interest to declare regarding this study.

\section{Authors' Contributions}

$\mathrm{KHB}$ and LHJ were the major contributors in writing the manuscript and performing experiment, PJH contributed to the drafting the manuscript, PSG was involved in drafting, writing and editing the manuscript, and reviewed the manuscript as the corresponding author. All Authors read and approved the final manuscript.

\section{Acknowledgements}

This study was supported by research fund from Chosun University, 2016.

\section{References}

1 Siegel RL, Miller KD and Jemal A: Cancer statistics. CA Cancer J Clin 66(1): 7-30, 2016. PMID: 26742998. DOI: 10.3322/ caac. 21332

2 Van Cutsem E, Cervantes A, Adam R, Sobrero A, Van Krieken JH, Aderka D, Aranda Aguilar E, Bardelli A, Benson A, Bodoky G, Ciardiello F, D'Hoore A, Diaz-Rubio E, Douillard JY, 
Ducreux M, Falcone A, Grothey A, Gruenberger T, Haustermans K, Heinemann V, Hoff P, Köhne CH, Labianca R, Laurent-Puig P, Ma B, Maughan T, Muro K, Normanno N, Österlund P, Oyen WJ, Papamichael D, Pentheroudakis G, Pfeiffer P, Price TJ, Punt C, Ricke J, Roth A, Salazar R, Scheithauer W, Schmoll HJ, Tabernero J, Taïeb J, Tejpar S, Wasan H, Yoshino T, Zaanan A and Arnold D: ESMO consensus guidelines for the management of patients with metastatic colorectal Cancer. Ann Oncol 27(8): 1386-1422, 2016. PMID: 27380959. DOI: 10.1093/annonc/ mdw235

3 Tell G, Quadrifoglio F, Tiribelli C and Kelley MR: The many functions of APE1/Ref-1: not only a DNA repair enzyme. Antioxid Redox Signal 11(3): 601-620, 2009. PMID: 18976116. DOI: $10.1089 /$ ars.2008.2194

4 Yang S, Irani K, Heffron SE and Jurnak F: Alterations in the expression of the apurinic/apyrimidinic endonuclease-1/redox factor-1 (APE/Ref-1) in human melanoma and identification of the therapeutic potential of resveratrol as an APE/Ref-1 inhibitor. Mol Cancer Ther 4(12): 1923-1935, 2005. PMID: 16373707. DOI: $10.1158 / 1535-7163 . M C T-05-0229$

5 Kelley MR, Cheng L, Foster R, Tritt R, Jiang J, Broshears J and Koch M: Elevated and altered expression of the multifunctional DNA base excision repair and redox enzyme Ape1/ref-1 in prostate cancer. Clin Cancer Res 7(4): 824-830, 2001. PMID: 11309329.

6 Zhang Y, Wang J, Xiang D, Wang and Xin X: Alterations in the expression of the apurinic/apyrimidinic endonuclease-1/redox factor-1 (APE1/Ref-1) in human ovarian cancer and indentification of the therapeutic potential of APE1/Ref-1 inhibitor. Int J Oncol 35(5): 1069-1079, 2009. PMID: 19787261. DOI: 10.3892/ijo_00000422

7 Kim MH, Kim HB, Yoon SP, Lim SC, Cha MJ, Jeon YJ, Park SG, Chang IY and You HJ: Colon cancer progression is driven by APEX1-mediated upregulation of Jagged. J Clin Invest 123(8): 3211-3230, 2012. PMID: 23863623. DOI: $10.1172 / \mathrm{J}$ CI65521

8 Sugiyama M, Oki E, Nakaji Y, Tsutsumi S, Ono N, Nakanishi R, Sugiyama M, Nakashima Y, Sonoda H, Ohgaki K, Yamashita N, Saeki H, Okano S, Kitao H, Morita M, Oda Y and Maehara Y: High expression of the Notch ligand Jagged-1 is associated with poor prognosis after surgery for colorectal cancer. Cancer Sci 107(10): 1705-1716, 2016. PMID: 27589478. DOI: 10.1111/cas.13075

9 Kim HB, Cho WJ, Choi NG, Kim SS, Park JH, Lee HJ and Park SG: Clinical implications of APEX1 and Jagged1 as chemoresistance factors in biliary tract cancer. Ann Surg Treat Res 92(1): 15-22, 2017. PMID: 28090501. DOI: 10.4174/ astr.2017.92.1.15

10 Penton AL, Leonard LD and Spinner NB: Notch signaling in human development and disease. Semin Cell Dev Biol 23(4): 450-457, 2012. PMID: 22306179. DOI: 10.1016/j.semcdb. 2012.01.010

11 Schroeter EH, Kisslinger JA and Kopan R: Notch-1 signalling requires ligand-induced proteolytic release of intracellular domain. Nature 393(6683): 382-386, 1998. PMID: 9620803. DOI: $10.1038 / 30756$

12 Yin L, Velazquez OC and Liu ZJ: Notch signaling: emerging molecular targets for cancer therapy. Biochem Pharmacol 80(5): 690-701, 2010. PMID: 20361945. DOI: 10.1016/j.bcp.2010.03.026

13 Miele L, Golde T and Osborne B: Notch signaling in cancer. Curr Mol Med 6(8): 905-918, 2006. PMID: 17168741. DOI: $10.2174 / 156652406779010830$
14 Heidelberger C, Chaudhuri NK, Danneberg P, Mooren D, Griesbach L, Duschinsky R, Schnitzer RJ, Pleven E and Scheiner J: Fluorinated pyrimidines, a new class of tumourinhibitory compounds. Nature 179(4561): 663-666, 1957. PMID: 13418758. DOI: $10.1038 / 179663 \mathrm{a} 0$

15 Ullman B, Lee M, Martin DW Jr. and Santi DV: Cytotoxicity of 5-fluoro-2'-deoxyuridine: requirement for reduced folate cofactors and antagonism by methotrexate. Proc Natl Acad Sci 75(2): 980-983, 1978. PMID: 147465. DOI: 10.1073/pnas. 75.2 .980

16 Kunimoto T, Nitta K, Tanaka T, Uehara N, Baba H, Takeuchi M, Yokokura T, Sawada S, Miyasaka T and Mutai M: Antitumor activity of 7-ethyl-10-(4-(1-piperidino)-1-piperidino)carbonyloxy-camptothecin, a novel water-soluble derivative of camptothecin, against murine tumors. Cancer Res 47(22): 59445947, 1987. PMID: 3664496.

17 Kidani Y, Noji M and Tashiro T: Antitumor activity of platinum (II) complexes of 1,2-diamino-cyclohexane isomers. Gan 1(5): 637-643, 1980. PMID: 7227714.

18 Colucci G, Gebbia V, Paoletti G, Giuliani F, Caruso M, Gebbia N, Cartenì G, Agostara B, Pezzella G, Manzione L, Borsellino N, Misino A, Romito S, Durini E, Cordio S, Di Seri M, Lopez M, Maiello E, Montemurro S, Cramarossa A, Lorusso V, Di Bisceglie M, Chiarenza M, Valerio MR, Guida T, Leonardi V, Pisconti S, Rosati G, Carrozza F, Nettis G, Valdesi M, Filippelli G, Fortunato S, Mancarella S and Brunetti C; Gruppo Oncologico Dell'Italia Meridionale: Phase III randomized trial of FOLFIRI versus FOLFOX4 in the treatment of advanced colorectal cancer: a multicenter study of the Gruppo Oncologico Dell'Italia Meridionale. J Clin Oncol 23(22): 4866-4875, 2005. PMID: 15939922. DOI: 10.1200/JCO.2005.07.113

19 Tournigand C, André T, Achille E, Lledo G, Flesh M, MeryMignard D, Quinaux E, Couteau C, Buyse M, Ganem G, Landi B, Colin P, Louvet C and de Gramont A: FOLFIRI followed by FOLFOX6 or the reverse sequence in advanced colorectal cancer: a randomized GERCOR study. J Clin Oncol 22(2): 229237, 2004. PMID: 14657227. DOI: 10.1200/JCO.2004.05.113

20 Gustavsson B, Carlsson G, Machover D, Petrelli N, Roth A, Schmoll HJ, Tveit KM and Gibson F: A review of the evolution of systemic chemotherapy in the management of colorectal cancer. Clin Colorectal Cancer 14(1): 1-10, 2015. PMID: 25579803. DOI: 10.1016/j.clcc.2014.11.002

21 Tveit KM1, Guren T, Glimelius B, Pfeiffer P, Sorbye H, Pyrhonen S, Sigurdsson F, Kure E, Ikdahl T, Skovlund E, Fokstuen T, Hansen F, Hofsli E, Birkemeyer E, Johnsson A, Starkhammar H, Yilmaz MK, Keldsen N, Erdal AB, Dajani O, Dahl $\mathrm{O}$ and Christoffersen T: Phase III trial of cetuximab with continuous or intermittent fluorouracil, leucovorin, and oxaliplatin (Nordic FLOX) versus FLOX alone in first-line treatment of metastatic colorectal cancer: the NORDIC-VII study. J Clin Oncol 30(15): 1755-1762, 2012. PMID: 22473155. DOI: 10.1200/JCO.2011.38.0915

22 Stintzing S, Modest DP, Rossius L, Lerch MM, von Weikersthal LF, Decker T, Kiani A, Vehling-Kaiser U, Al-Batran SE, Heintges T, Lerchenmüller C, Kahl C, Seipelt G, Kullmann F, Stauch M, Scheithauer W, Held S, Giessen-Jung C, Moehler M, Jagenburg A, Kirchner T, Jung A and Heinemann V: FIRE-3 investigators. FOLFIRI plus cetuximab versus FOLFIRI plus bevacizumab for metastatic colorectal cancer (FIRE-3): a posthoc analysis of tumour dynamics in the final RAS wild-type 
subgroup of this randomised open-label phase 3 trial. Lancet Oncol 17(10): 1426-1434, 2016. PMID: 27575024. DOI: 10.1016/S1470-2045(16)30269-8

23. $\mathrm{Hu} \mathrm{T}, \mathrm{Li} \mathrm{Z}, \mathrm{Gao} \mathrm{CY}$ and $\mathrm{Cho} \mathrm{CH}$ : Mechanisms of drug resistance in colon cancer and its therapeutic strategies. World $\mathrm{J}$ Gastroenterol 22(30): 6876-6889, 2016. PMID: 27570424. DOI: 10.3748/wjg.v22.i30.6876

24 Holohan C, Van Schaeybroeck S, Longley DB, and Johnston PG: Cancer drug resistance: an evolving paradigm. Nat Rev Cancer 13(10): 714-726, 2013. PMID: 24060863. DOI: 10.1038/nrc3599

25 Steg AD, Katre AA, Goodman B, Han HD, Nick AM, Stone RL, Coleman RL, Alvarez RD, Lopez-Berestein G, Sood AK and Landen CN: Targeting the notch ligand JAGGED1 in both tumor cells and stroma in ovarian cancer. Clin Cancer Res 17(17): 5674-5685, 2011. PMID: 21753153. DOI: 10.1158/10780432.CCR-11-0432

26 Yoon HA, Noh MH, Kim BG, Han JS, Jang JS, Choi SR, Jeong JS and Chun JH: Clinicopathological significance of altered Notch signaling in extrahepatic cholangiocarcinoma and gallbladder carcinoma. World J Gastroenterol 17(35): 4023 4230, 2011. PMID: 22046092. DOI: 10.3748/wjg.v17.i35.4023

27 Li D, Masiero M, Banham AH and Harris AL: The notch ligand JAGGED1 as a target for anti-tumor therapy. Front Oncol 4: 254, 2014. PMID: 25309874. DOI: 10.3389/fonc.2014.00254

28 Wang Z, Li Y, Ahmad A, Azmi AS, Banerjee S, Kong D and Sarkar FH: Targeting Notch signaling pathway to overcome drug resistance for cancer therapy. Biochim Biophys Acta 1806(2): 258-267, 2010. PMID: 20600632. DOI: 10.1016/j.bbcan.2010. 06.001

29 Koduru S, Kumar R, Srinivasan S, Evers MB and Damodaran C: Notch-1 inhibition by Withaferin-A: a therapeutic target against colon carcinogenesis. Mol Cancer Ther 9(1): 202-210, 2010. PMID: 20053782. DOI: 10.1158/1535-7163.MCT-09-0771

30 Guilmeau S, Flandez M, Mariadason JM and Augenlicht LH: Heterogeneity of Jagged1 expression in human and mouse intestinal tumors: implications for targeting Notch signaling. Oncogene 29(7): 992-1002, 2010. PMID: 19935714. DOI: 10.1038/onc. 2009.393
31 Matsui WH: Cancer stem cell signaling pathways. Medicine (Baltimore) 95: S8-S19, 2016. PMID: 27611937. DOI: 10.1097/MD.0000000000004765

32 Artavanis-Tsakonas S, Rand MD, and Lake RJ: Notch signaling: cell fate control and signal integration in development. Science 284(5415): 770-776, 1999. PMID: 10221902. DOI: 10.1126/ science.284.5415.770

33 Venkatesh V, Nataraj R, Thangaraj GS, Karthikeyan M, Gnanasekaran A, Kaginelli SB, Kuppanna G, Kallappa CG and Basalingappa KM: Targeting Notch signalling pathway of cancer stem cells. Stem Cell Investig 5: 5, 2018. PMID: 29682512. DOI: $10.21037 /$ sci.2018.02.02

34 O'Brien CA, Pollett A, Gallinger S and Dick JE: A human colon cancer cell capable of initiating tumour growth in immunodeficient mice. Nature 445(7123): 106-110, 2007. PMID: 17122772. DOI: 10.1038/nature05372

35 Puglisi MA, Tesori V, Lattanzi W, Gasbarrini GB and Gasbarrini A: Colon cancer stem cells: controversies and perspectives. World J Gastroenterol 19(20): 2997-3006, 2013. PMID: 23716979. DOI: $10.3748 /$ wjg.v19.i20.2997

36 Kozovska Z, Gabrisova V and Kucerova: Colon cancer: cancer stem cells markers, drug resistance and treatment. Biomed Pharmacother 68(8): 911-916, 2014. PMID: 25458789. DOI: 10.1016/j.biopha.2014.10.019
Received September 17, 2019

Revised October 2, 2019

Accepted October 4, 2019 